\title{
On Paper Partition Chromatography of Proteins and Carbohydrates from Carcinomatous and Non- carcinomatous Tissues and Body Fluids
}

\author{
By \\ Hirosi Tiba and Sumio Isikawa \\ (千蓝博) (不川 澄 雄) \\ From the Medical Clinic of Prof. T. Kurokawa, \\ Tohoku University, Sendai
}

(Received for publication, February 12, 1954)

Investigations on the group carbohydrates from gastric cancer and gastric mucosa were reported by Masamune and his cooperators ${ }^{12) 31}$.

Tiba') has prepared proteins which are active pharmacologically and serologically from the carcinomatous and non-carcinomatous tissues and body fluids.

To identify sugar and amino acid components in these materials, the writers made use of paper partition chromatography.

\section{EXPERIMENTAL}

I. Experiments regarding the Sugar Components

Technique

Paper partition chromatography of sugar was attempted this time in the descending way which served the purpose more than in the ascending.

Then the chromatography proceeded according to Masamune and Yosizawa. ${ }^{5)}$ Toyo filter paper No. 2 is cut into strips of $60 \mathrm{~cm} . \times 5 \mathrm{~cm}$. for standard and the hydrolysate of materials.

Sampling

Of a solution, containing sugars in concentration of $2 \%$ with respect to each individual sugar and acidulated to $\mathrm{pH} 5.8$ with a dilute $\mathrm{H}_{2} \mathrm{SO}_{4}$ $(0.1 \mathrm{~N}$.), was pipetted $0.013-0.015 \mathrm{cc}$. on a paper strip at a distance of $10 \mathrm{~cm}$. from the upper edge. Sugars to be used were glucosamine hydrochloride (crystalline), galactose (E. Merck), mannose (Tanabe) and rhamnose (Tanabe).

About $30-40 \mathrm{cc}$. of the solvent was placed first in the trough and supplemented during irrigation. The solvent for irrigation was butanolpyridine-water $(5: 3: 2)$ solution. In this case, aniline hydrogen phthalate 
Fig. 1

Protein of Gastric Juice

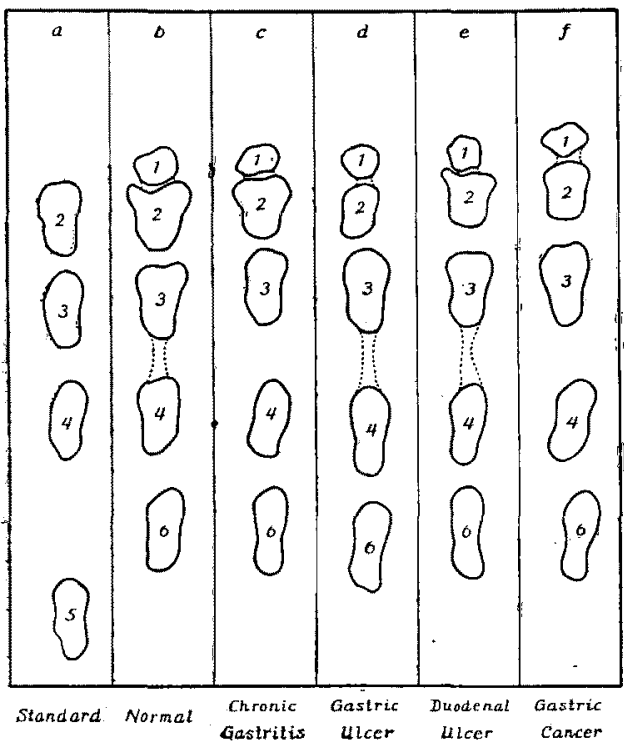

Fig. 2

Drotein and Cornonyerail ol Gosiru Muroso

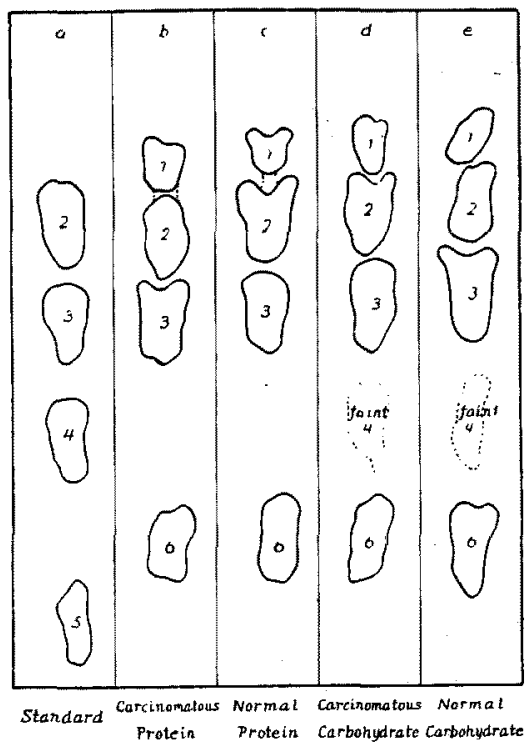

Fig. 1. Butanol-pyridine-water $(5: 3: 2)$ chromatograms of the hydrolysate of proteins in gastric juice. Indicator: aniline hydrogen phthalate of Partridge. Duration of test, $24 \mathrm{hrs}$, temp., $27^{\circ} \pm 1^{\circ} \mathrm{C}$.

$\mathrm{a}$ : standard, b : normal gastric juice protein, $\mathrm{c}$ : chronic gastritis juice protein, $\mathrm{d}$ : gastric ulcer juice protein, e: duodenal ulcer juice protein, $\mathrm{f}$ : gastric cancer juice protein. 1 : chondrosamine, $2:$ glucosamine, 3 : galactose, $4:$ mannose, $5:$ rhamnose, $6:$ l-fucose.

Fig. 2. Butanol-pyridine-water $(5: 3: 2)$ chromatograms of the hydrolysate of proteins and carbohydrates in gastric cancer and gastric mucosa. Indicator, duration of test and temperature same as in Fig. 1.

$\mathrm{a}$ : standard, $\mathrm{b}$ : gastric cancer protein, $\mathrm{c}$ : normal mucosa protein, $\mathrm{d}$ : gastric cancer carbohydrate, e: normal mucosa carbohydrate.

Ciphers express the same as in Fig. 1.

in butanol (reagent of Partridge $\left.{ }^{6}\right)$ was used as an additional developer.

\section{Materials}

1) Preparations of the proteins from gastric juice of 5 groups, namely normal, chronic gastritis, gastric ulcer, duodenal ulcer and gastric cancer.

2) Preparations of the proteins from gastric cancer and normal gastric mucosa. These were prepared formerly by Tiba').

3) Preparations of the carbohydrates from gastric cancer and gastric mucosa

(a) Carbohydrate of gastric cancer, (C-ch). Tumor tissue was dissected from gastric cancers and cut into small pieces to preserve in about 
Fig. 3

Protein and Carbohydrate of Ascitic Fluid

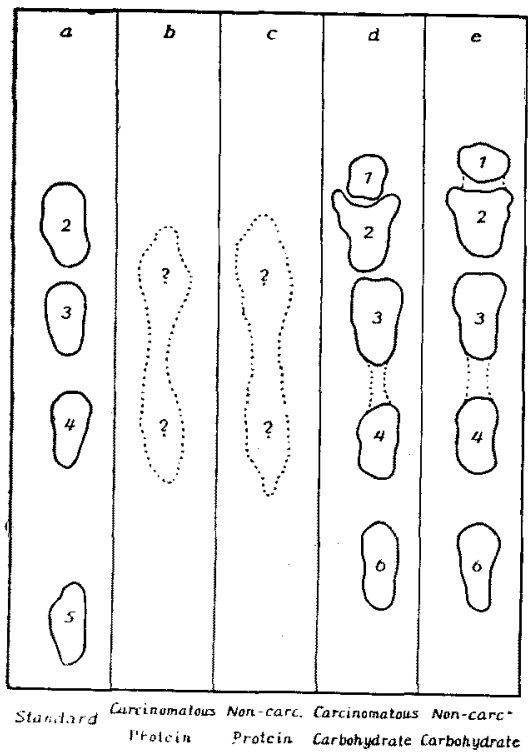

Fig. 4

Protein of Placenta

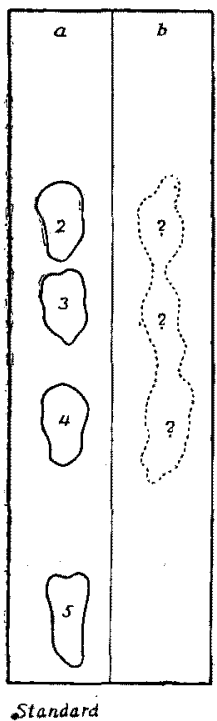

Fig. 3. Butanol-pyridine-water $(5: 3: 2)$ chromatograms of the hydrolysate of proteins and carbohydrates in carcinomatous and non-carcinomatous ascitic fluids. Indicator, duration of test and temperature same as in Fig. 1. a : standard, b : carcinomatous protein, $\mathrm{c}$ : non-carcinomatous protein,

$\mathrm{d}$ : carcinomatous carbohydrate, e: non-carcinomatous carbohydrate.

Ciphers express the same as in Fig. 1.

Fig. 4. Butanol-pyridine-water $(5: 3: 2)$ chromatograms of the hydrolysate of placental protein. Indicator, duration of test and temperature same as' in 1 Fig. 1.

$\mathrm{a}:$ standard, $\mathrm{b}$ : protein of placenta.

Ciphers express the same as in Fig. 1.

7. volumes of $95 \%$ alcohol for the purpose of dehydration. $150 \mathrm{~g}$. of the tissue thus dehydrated was masticated, dried in a vacuum desiccator $\left(\mathrm{H}_{2} \mathrm{SO}_{4}\right)$ and pulverized in a mortar. Fibers removed, the remaining powder amounted to $34 \mathrm{~g}$. The preparation proceeded as follows :

It was stirred with 20 volumes of water for 3 days, using toluene as a preservative, and centrifuged. The residue was treated likewise three times, until no more substance came out. The centrifuged supernatant liquids collected were distilled to about $200 \mathrm{cc}$. To that extract was added the saturated $\mathrm{Ba}(\mathrm{OH})_{2}$ to cause maximum precipitation (the $\mathrm{pH}$ was shifted to 9.0) and centrifuged. The supernatant liquid was acidified by

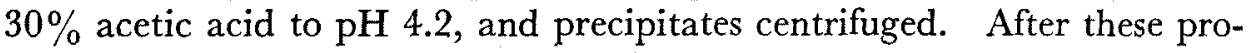
cesses, barium was taken out with just sufficient amount of sulfuric acid 
Fig. 5

Normat Gastric Juice

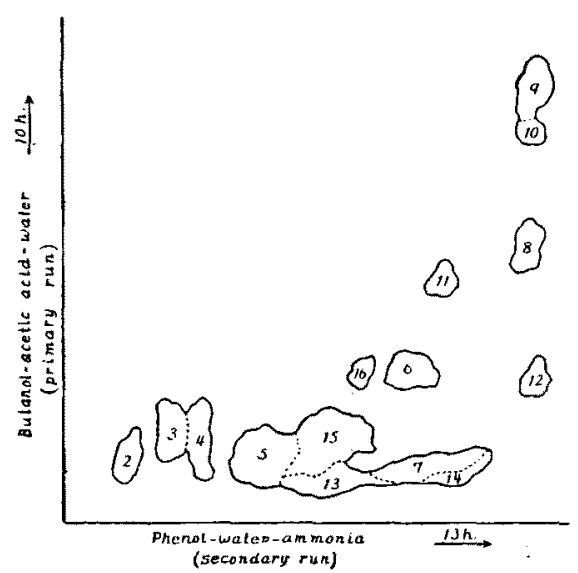

Fig. 6

Gastric Juice of Chronic Gastritis

Fig. 5. Butanol-acetic acid-water/phenol-water chromatogram of the hydrolysate of protein in nomral gastric juice developed with ninhydrin (temp., $20^{\circ} \pm 1^{\circ} \mathrm{C}$ ).

2: aspartic acid, $3:$ glutamic acid, $4:$ serine, $5:$ glycine, $6:$ alanine, $7:$ histidine, $8:$ valine or methionine, $9:$ leucine or isoleucine, 10 : phenyl-alanine, 11: tyrosine, $12:$ proline, 13:lysine, $14:$ arginine, 15 : hexosamine, 16 : threonine.

Fig. 6. Butanol-acetic acid-water/phenol-water chromatogram of the hydrolysate of protein in gastric juice due to chronic gastritis. 2-16 signify the corresponding numbers in Fig. 5.

$(1 \mathrm{~N})$. The centrifuged supernatant liquid was made neutral with $\mathrm{NaOH}(0.05 N)$. To this liquid $\left(\mathrm{NH}_{4}\right)_{2} \mathrm{SO}_{4}$ was added at $1 / 2$ saturation of the salt $\left(20^{\circ} \mathrm{C}\right)$, and slight turbidity appeared.

The powder of $\left(\mathrm{NH}_{4}\right)_{2} \mathrm{SO}_{4}$ was added to it at full saturation $\left(20^{\circ} \mathrm{C}\right)$ that precipitation was most evident. It stood at $20^{\circ} \mathrm{C}$ for 30 minutes. The flocculent precipitate was centrifuged off. The supernatant liquid was dialyzed through cellophane against running water for 3 days and condensed to a syrup, precipitated with alcohol and dried. The dried material was dissolved in $20 \mathrm{cc}$. of water and the powder of $\left(\mathrm{NH}_{4}\right)_{2} \mathrm{SO}_{4}$ at full saturation was added. It stood for about 30 minutes. The transparent solution freed from some precipitates that appeared was dialyzed for 3 days. It was then eliminated from some precipitate which had appeared, and $10 \%$ lead acetate was added until the maximum precipitation took place. It was centrifuged and filtrated through a creased paper. $\mathrm{H}_{2} \mathrm{~S}$ gas passed sufficiently through the filtrate to take off lead completely. The precipitation was filtrated through a creased paper. The filtrate was dis- 
Fig. 7

Gastric duice of Gastric ulcer

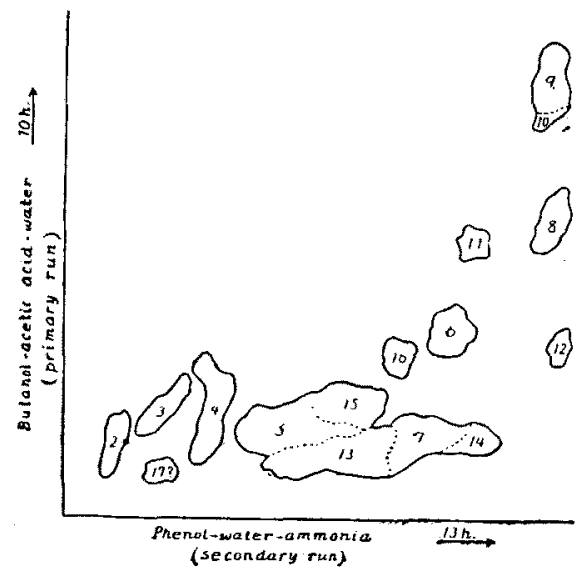

Fig. 8

Gastric Juice of Duodenat ulcer

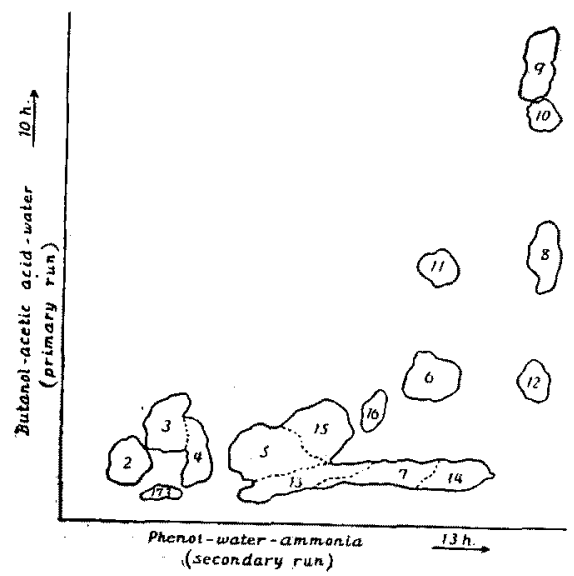

Fig. 7. Butanol-acetic acid-water/phenol-water chromatogram of the hydrolysate of protein in gastric juice due to gastric ulcer.

2-16 signify the corresponding numbers in Fig. 5. and 17 expresses under-glutamic acid (?).

Fig. 8. Butanol-acetic acid-water/phenol-water chromaotgram of the hydrolysate of protein in gastric juice due to doudenal ulcer.

2-17 signify the corresponding numbers in Figs. 5 and 7.

tilled to a syrupy consistency, precipitated with alcohol and dried.

The product was taken up in $50 \mathrm{cc}$. of water and electrodialyzed (180 Volts) for 24 hours. The trace of precipitation that had appeared was centrifuged off. The supernatant liquid was distilled, precipitated with alcohol, and dried. The white powder was given.

b) Carbohydrate of gastric mucosa (M-ch). Carbohydrate of gastric mucosa was treated in a similar manner as in the above (C-ch).

\section{Chemical properties}

Qualitative assays gave the following results:

$\begin{array}{lcc} & \text { C-Ch } & \text { M-Ch } \\ \text { Biuret } & - & - \\ \text { Molish } & \text { \# } & \text { \# } \\ \text { Ninhydrin } & \pm & \pm \\ \text { Phosphorus } & - & - \\ \text { Neuberg-Saneyoshi } & - & -\end{array}$

\pm : faintly positive, $\mathbb{H}$ : strongly positive, - : negative.

Quantitative analysis. C-Ch.: Nitrogen (micro Kjeldahl) $4.3 \%$, hexosamine (Blix method ${ }^{7)}$ ) $36.6 \%$, ash $0.8 \%$.

M-Ch : Nitrogen $4.6 \%$, hexosamine $34.8 \%$, ash $1.3 \%$. 
Fig. 9

Gastric Sulice of Gastric cancer

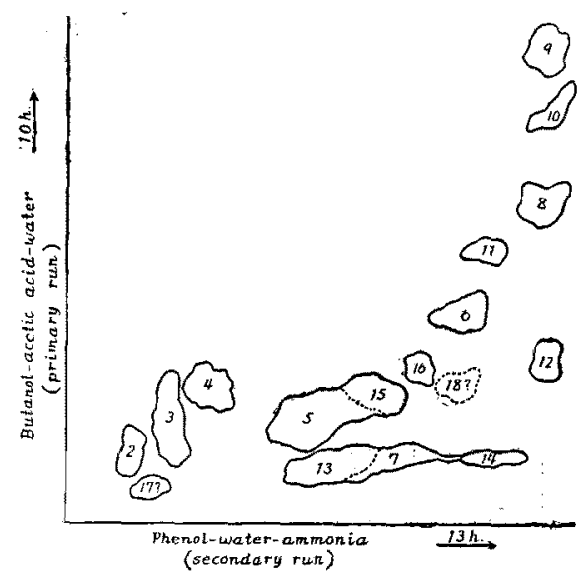

Fig. 10

Normal Gastric Mucosa.,

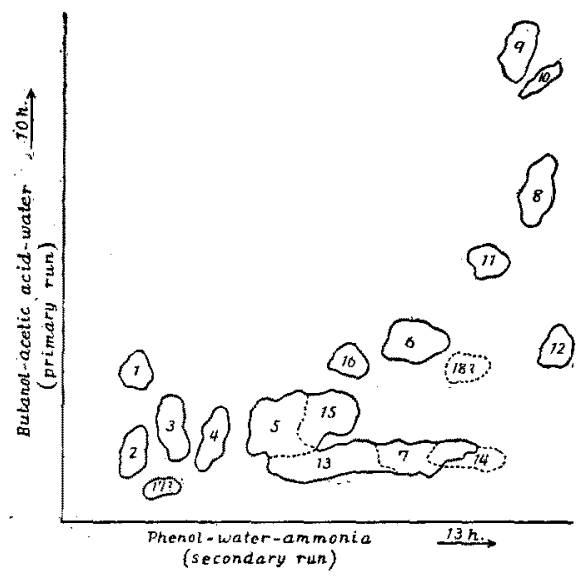

Fig. 9. Butanol-acetic acid-water/phenol-water chromatogram of the hydrolysate of protein in gastric juice due to gastric cancer.

2-17 signify the corresponding numbers in Figs. 5 and 7, and 18 expresses an unknown spot.

Fig. 10. Butanol-acetic acid-water/phenol-water chromatogram of the hydrolysate of protein in normal gastric mucosa.

1: cysteic acid, 2-18: signify the corresponding numbers in Figs. 5, 7 and 9.

4) Preparations of the proteins and carbohydrates from the carcinomatous and non-carcinomatous ascitic fluids.

These materials were prepared by the procedure of Tiba et al. ${ }^{81}$ at the Medico-chemical Institute of Prof. H. Masamune.

5) Preparation of the protein from placenta.

This was reported in the previous paper ${ }^{4}$.

In all the cases hydrolysis of the materials and subsequent preparation of the solution for chromatography was carried out as follows:

$30 \mathrm{mg}$. in the cases of carbohydrates, $50-100 \mathrm{mg}$. in the cases of proteins from the specimens mentioned above were hydrolyzed with 3-5 cc. of $1 \mathrm{~N} \mathrm{H}_{2} \mathrm{SO}_{4}$ in an ampoule by heating at $100^{\circ} \mathrm{G}$ for about 5 hours. The hydrolysates nearly neutralized till $\mathrm{pH} 5.8$ with baryta and the supernatant liquid was condensed to about $0.5 \mathrm{cc}$. From this condensate 0.02 and $0.03 \mathrm{cc}$. portion was sampled.

\section{Results}

As Figs. 1 and 3 (d, e) show, proteins from gastric juice of 5 groups and carbohydrates from ascitic fluids contained chondrosamine, gluco- 
Fig. 11

Carciñomatous Gastric Mucosa

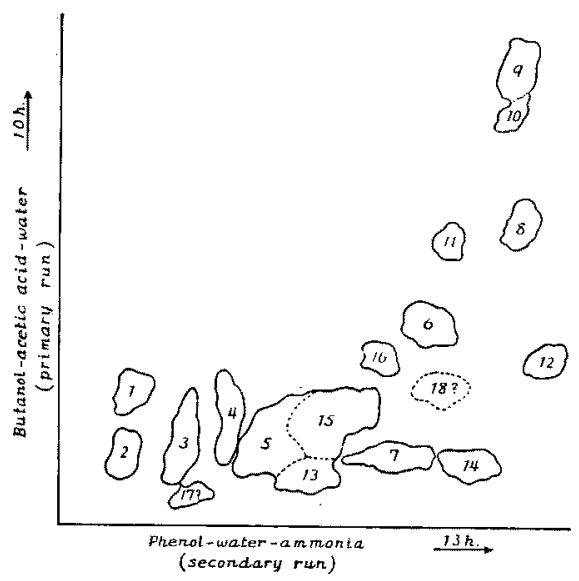

Fig. 12

Non-Carrithomatous Ascilic fruid

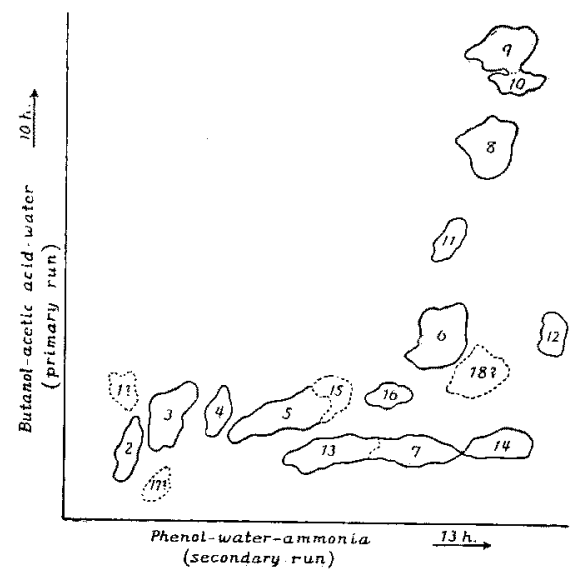

Fig. 11. Butanol-acetic acid-water/phenol-water chromatogram of the hydrolysate of protein in gastric cancer. Ciphers express the same as in Fig. 10 .

Fig. 12. Butanol-acetic acid-water/phenol-water chromatogram of the hyd o'ysate of protein in non-carcinomatous ascitic fluid.

Ciphers express the same as in Fig. 10.

Fig. 13

Carcinomatous Ascitic Fiutd

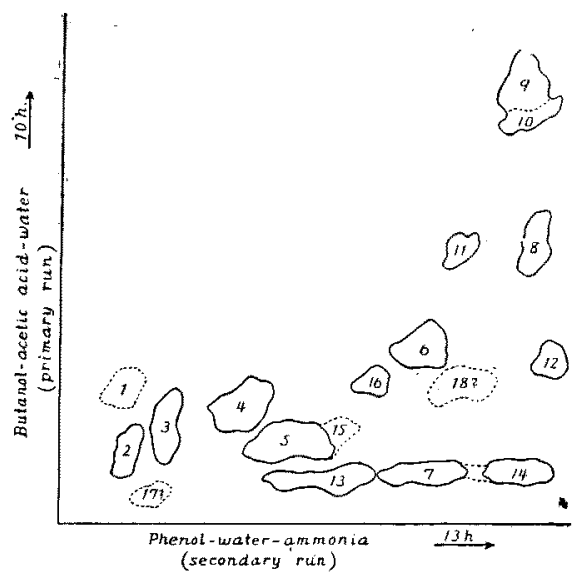

Fig. 14

Placental substance

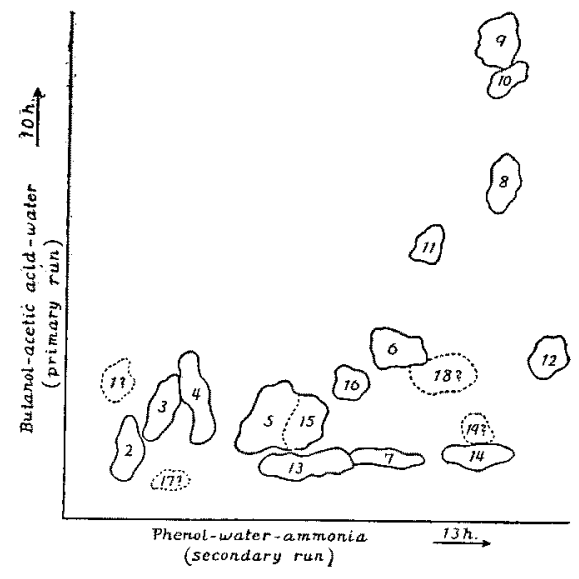

Fig. 13. Butanol-acetic acid-water/phenol-water chromatogram of the hydrolysate of protein in carcinomatous ascitic fluid.

Ciphers express the same as in Fig. 10.

Fig. 14. Butanol-acetic acid-water/phenol-water chromatogram of the hydrolysate of placental protein.

1-18 signify the same as in Fig. 10 and 19 expresses an unknown spot. 
samine, galactose, mannose and l-fucose.

And in Fig. 2, proteins and carbohydrates from gastric cancer and normal gastric mucosa revealed the presence of chondrosamine, glucosamine, galactose, 1-fucose and faint mannose. But as in Figs. 3 (b, c) and 4, proteins of ascitic fluids and placenta demonstrated very indistinct colored areas, probably due to the lack of sugar content.

\section{Experiments on Amino Acid Components}

\section{Technique}

To identify the probable amino acids, $30 \mathrm{mg}$. each of specimens were refluxed in a boiling water bath, with $6 \mathrm{~N} \mathrm{HCl}$ for 48 hours. The hydrolysates were evaporated to dryness on a water bath and the residues were evaporated many times with water to remove $\mathrm{HCl}$ as far as possible. Finally these were taken up in water, freed from the insoluble part and condensed to $0.3-0.4 \mathrm{cc}$. $0.05-0.08 \mathrm{cc}$. respectively were put on the paper, and primarily run (ascending) with butanol-acetic acid-water $(4: 1: 5)$, secondarily run with phenol-water $(4: 1)$ in an atmosphere saturated with ammonia.

\section{Results}

Figs. 5-14 illustrate the aquired chromatograms diagramatically.

\section{SUMMARY}

1. The sugar and amino acid components of the proteins and the carbohydrates from carcinomatous and non-carcinomatous tissues and body fluids were identified by paper partition chromatography.

The present findings indicated that the corresponding proteins and carbohydrates of carcinomatous and non-carcinomatous tissues and body fluids are resembled each other.

2. The carbohydrates were prepared from gastric cancers and human gastric mucosa, and their properties were investigated.

\section{References}

1) Satoh, Tohoku J. Exp. Med., 1949, 51, 275.

2) Oh-Uti, ibid., 1949, 51, 297.

3) Masamune, Yosizawa \& Masukawa, ibid., 1953, 58, 381.

4) Tiba, ibid., ibid., this volume, p. 211.

5) Masamune \& Yosizawa, ibid., 1953, 59, 1.

6) Partridge, Nature, 1949, 164, 443.

7) Blix, Acta chem. Scand., 1948, 2, 468.

8) Masamune, Tiba, Takaku, Kikuchi \& Satoh, Tohoku J. Exp. Med., 1953, 59, 87. 